\title{
GOVERNO DE CRIANÇAS: O INSTITUTO PROFISSIONAL JOÃO ALFREDO (1910-1933)
}

\author{
Maria Zélia Maia de Souza \\ Universidade Federal de Minas Gerais, Brasil.
}

\begin{abstract}
Resumo Profissional João Alfredo (1910/1933), ancorando-se nas reflexões de Michel Foucault. Nesse no interior da instituição analisada. O exame da documentação referente ao Instituto permitiu perceber que esse campo de saber foi parte integrante das táticas de governo executadas pelos gestores da instituição, as quais buscavam manter a sua normalidade, enquanto instituição pensada e implementada para abrigar e profissionalizar meninos pobres, embora não exclusivamente.

Palavras-chave: menores, trabalho, futebol, Instituto Profissional João Alfredo.

\section{GOVERNMENT FOR CHILDREN: THE PROFESSIONAL INSTITUTE JOÃO ALFREDO (1910-1933)}

Nesse estudo se realiza uma análise das ações de governo de crianças no espaço do Instituto sentido, é feita uma reflexão acerca dos sentidos da ginástica escolar e do lugar do jogo de futebol

Abstract

This study undertakes an analysis of government action of children within the Professional Institute João Alfredo (1910-1933), anchoring on the thinking of Michel Foucault. In this sense, there is a reflection on the sense of place and school gymnastics and football game in this field of knowledge within the institution analyzed. The examination of documentation, relating to the Institute, allowed realize that this field of knowledge was an integral part of the tactics of government run by the managers of the institution which sought to maintain normalcy as an institution designed and implemented to accommodate professional and poor kids, but not exclusively. Keyworks: children, work, football; Instituto Profissional João Alfredo.

\section{GOBIERNO DE LA INFANCIA: EL PROFESIONAL INSTITUTO JOÃO ALFREDO (1910-1933)}

\section{Resumen}

Este estudio realiza un análisis de la acción del gobierno de los niños en el Instituto Profesional João Alfredo (1910-1933), el anclaje en el pensamiento de Michel Foucault. En este sentido, hay una reflexión sobre el sentido de la gimnasia y el lugar de la escuela y el juego de fútbol en este 
campo de conocimiento dentro de la institución analizada. El examen de la documentación, en relación con el Instituto, permite darse cuenta de que este campo de conocimiento era una parte integral de las tácticas de gobierno a cargo de los directivos de la institución que trataron de mantener nimalcy como una institución diseñada e implementada para dar cabida a profesionales y los niños pobres, pero no exclusivamente.

\title{
GOUVERNEMENT DES ENFANTS: L' INSTITUT PROFESSIONNELLE JOÃO ALFREDO (1910-1933)
}

\begin{abstract}
Résume
Cette étude a entrepris une analyse de l'action gouvernementale des enfants en l'espace de l'Institut de formation professionnelle João Alfredo (1910-1933), avec l'ancrage dans les pensées de Michel Foucault. En ce sens, est faite une réflexion sur les orientations de la gymnastique écolaire et de la place du jeu de football au sein de l'institution analysée. L'examen de la documentation concernant au Institut a permis de réaliser que cette connaissance fait partie intégrante de la tactique du gouvernement dirigé par les gestionnaires de l'institution, qui cherchait à maintenir sa normalité, comme une institution conçu et mis en œuvre comme maison et espace de professionnalisation des pauvres garçons, bien que pas exclusivement.

Mots-clé: enfants, travail, football, Institut Professionnel João Alfredo.
\end{abstract}

Pode deixar o menino sem cuidado. Aqui eles endireitam, saem feitos gente, dizia um velho alto e magro para o meu tio Juca, que me levara para o colégio de Itabaiana [...] Na cama começavam a chegar os meus pensamentos. Éramos seis no quarto pequeno de telha-vã. Ninguém podia trocar palavras. Falava-se aos cochichos, e para tudo lá vinha: é proibido. A liberdade silenciosa do engenho sofria ali amputações dolorosas. Acordar à hora certa, comer à hora certa, dormir à hora certa. (Rego, 1977, p. 38) 1

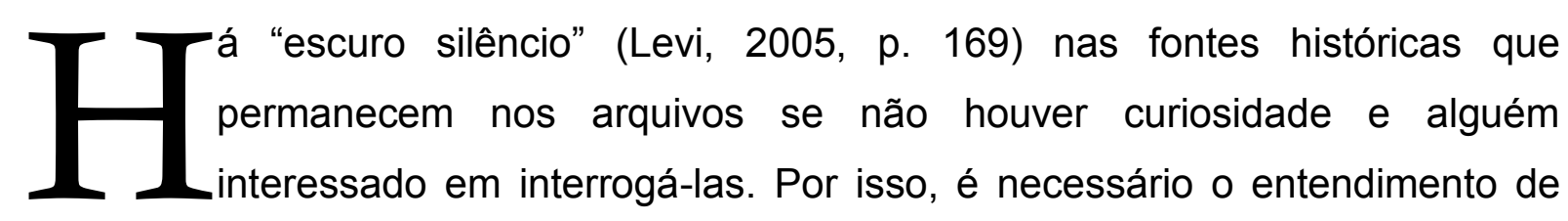
que os problemas de estudo são engendrados em um complexo processo histórico e que, por essa condição, não é natural (Veiga-Neto, 2003). Neste sentido, o pesquisador percorre uma seara em que passados e presentes se entrecruzam por meio da emergência e articulação de discursos produzidos em diferentes épocas e situações.

A chamada Primeira República brasileira se constitui em uma destas diferentes épocas. Tempo em que muitas formas escolares foram pensadas e algumas postas em

\footnotetext{
1 José Lins do Rêgo escreveu o romance Doidinho em 1933. Nele, descreve as experiências da vida de Carlos, personagem principal do romance, enquanto aluno interno do Instituto Nossa Senhora do Carmo, localizado em Itabaiana/PB.
} 
execução. Dentre elas ressalta-se, neste artigo, uma que pode ser caracterizada pelo trinômio assistência, instrução e profissionalização, presente na proposta do Instituto Profissional João Alfredo (IPJA) até $1933^{2}$

É importante esclarecer que o IPJA foi, anteriormente, o Asilo de Meninos Desvalidos, um estabelecimento pensado e estruturado para funcionar como casa, escola e oficina, tendo como propósito abrigar, educar e profissionalizar meninos pobres ou órfãos em regime de internato, na faixa etária compreendida entre seis e doze anos de idade. Funcionou de 1875 a 1894, na Chácara dos Macacos, na cidade do Rio de Janeiro. Em 1894, com o objetivo de dar ênfase à profissionalização de seus alunos, passou a denominar-se Instituto Profissional.

Entretanto, em 1898, este nome sofreu nova alteração, Instituto Profissional Masculino, buscando se distinguir do Instituto Profissional Feminino da mesma cidade. Somente em 1910 a instituição incorporou a denominação Instituto Profissional João Alfredo $^{3}$, em homenagem ao conselheiro João Alfredo Correia de Oliveira (1835-1915), seu fundador ainda no período imperial (Braga, 1925).

A instituição teve a sua primeira regulamentação estabelecida pelo decreto n. 31 , de 29 de dezembro de 1894, cujo artigo primeiro caracterizou o IPJA como um internato destinado a dar aos respectivos alunos a educação física, moral e prática necessária para o bom desempenho das profissões de que tratou o referido regulamento e o ensino seria gratuito e integral (Coleção de leis municipais, 1897).

De modo mais detalhado, este regulamento previa os seguintes cursos em seu artigo $2^{\circ}$ :

\begin{abstract}
Ciências e Letras ${ }^{4}$
Escrita e noções elementares da língua portuguesa, aritmética prática, instrução moral e cívica; língua portuguesa; noções elementares da língua francesa; elementos de história e geografia do Brasil; aritmética, noções de álgebra e geometria prática; noções de mecânica geral e de mecânica aplicada; noções elementares de física experimental e de química prática.
\end{abstract}

${ }^{2}$ Ao longo da história, esta instituição escolar/asilar recebeu várias denominações: Instituto Profissional (1894-1898); Instituto Profissional Masculino (1898-1910); Instituto Profissional João Alfredo (1910-1933); Escola Secundária Técnica João Alfredo (1933/1934); e Escola Técnica Secundária João Alfredo (1934/1956).

3 Após 1933, a instituição passou a integrar o sistema de ensino secundário. Nos anos de 1933 a 1934 , Escola Secundária Técnica João Alfredo e, entre 1934 e 1956, Escola Técnica Secundária João Alfredo. Com a criação da Universidade do Distrito Federal, tornou-se instituição complementar a ela, ligada ao Instituto de Artes. Atualmente, é o Colégio Estadual João Alfredo, onde se ministram o ensino médio, formação geral e ensino profissional na área de administração, com funcionamento em dois turnos: manhã e noite (Souza, 2008).

${ }^{4}$ A grafia foi atualizada para tornar a leitura mais fluente, sem comprometer a compreensão do texto. 


\section{Curso de Artes}

Desenho geométrico e de máquinas; desenho de ornatos e figuras; escultura; música vocal; música instrumental; ginástica; exercícios militares e de esgrima; trabalhos manuais: tecnologia das profissões elementares, manejo das principais ferramentas.

\section{Curso Profissional}

Tipografia; entalhadura.

Os ofícios de: alfaiate, carpinteiro, encanador, ferreiro e serralheiro; latoeiro, marceneiro e empalhador, sapateiro e torneiro. (Coleção de Leis Municipais, 1897, p. 170)

$\mathrm{O}$ art. $5^{\circ}$ estabelece uma ordem de prioridade para a matrícula nos cursos:

$\S 1^{\circ}$ Os menores que, nos estabelecimentos de assistência à infância desvalida, revelassem aptidão para o aprendizado profissional;

$\S 2^{\circ}$ Os filhos dos funcionários públicos;

$\S 3^{\circ}$ Os menores que nas escolas públicas do primeiro grau revelarem aproveitamento e aptidão para o dito aprendizado;

$\S 4^{\circ}$ Os filhos dos operários das oficinas do Estado e dos funcionários públicos que assim o requereram. (Coleção de leis municipais, 1897, p. 170)

Com relação aos documentos para a matrícula, o IPJA exigia certidão de idade, atestado médico, atestado de pobreza e aprovação no exame de admissão, em que os candidatos à vaga eram submetidos às provas de português, ditado e leitura, e matemática, prática das quatro operações. Seriam dispensados do exame aqueles menores que apresentassem certificados de estudos primários do primeiro grau $^{5}$ (parágrafo único).

Como previsto pelo mesmo regulamento, os menores internos em estabelecimentos de assistência à infância desvalida teriam prioridade para a matrícula no IPJA, desde que revelassem aptidão para o aprendizado profissional. Assim sendo, os alunos eram submetidos ao regime disciplinar de internato do Instituto, podendo-lhes ser aplicadas penas variadas, de advertências até expulsão. Deve-se salientar que o trabalho era compulsório e realizado nas oficinas do conjunto asilar/escolar.

De modo ilustrativo, a epígrafe que introduz este trabalho fornece pistas para imaginarmos a forma como se iniciava a vida de um jovem aluno em um internato, tomando como referente o Colégio de Itabaiana/PB e o protagonista deste romance de caráter autobiográfico, Carlos de Melo, personagem central do romance Doidinho. No IPJA, o início da vida de interno dos meninos se dava a partir dos requerimentos de

\footnotetext{
${ }^{5}$ As coordenadas gerais traçadas pela reforma educacional realizada por Benjamim Constant em 1890 estabeleceram a divisão do ensino primário na Capital Federal em dois graus. Por esta reforma, a escola primária de primeiro grau organizou-se em três cursos: elementar (de 6 a 9 anos), médio (de 9 a 11 anos) e superior (de 11 a 13 anos). Para ingressar no curso primário de segundo grau, era necessário o certificado de estudos do primeiro (Veiga, 2007, p. 239).
} 
matrícula, encaminhados por diferentes sujeitos ao diretor do estabelecimento ou ao prefeito do antigo Distrito Federal.

Da parte das famílias, alguns exemplos de pedido de matrícula ilustram a demanda a que me referi anteriormente:

Ex-professor de musica do Asilo de Meninos Desvalidos, hoje Instituto Profissional, desejando dar educação e instrução profissional a seu filho Raul, de 12 anos de idade, como prova com a certidão junta, e não podendo fazê-lo por the faltarem os recursos, vem requerer-vos que, submetido o dito seu filho do exame de que trata o regulamento em vigor, Ihe conceda a matricula nesse estabelecimento. (Arquivo do Asylo, 1897, pasta 42)

Outro exemplo data do ano de 1908 e foi feito por José Correia Pinto, avô de Osvaldo Correia Pinto, de 13 anos de idade, natural do Estado de Minas Gerais, órfão de pai e mãe (Arquivo do Asylo de Meninos Desvalidos - pasta 063). Extrapola o grupo familiar o pedido de matrícula para Alberto Gomes de Oliveira, do Estado de São Paulo, feito por Leôncio de Carvalho, ex ministro do Império. Alberto era também órfão de pai e mãe, pardo, com 13 anos de idade, cujo pai era militar. Teve a sua matrícula efetivada em 3 de julho de 1908. Na sua pasta/dossiê não consta o atestado de pobreza, documento exigido para a efetivação da matrícula. O fato é que este aluno foi desligado em 16 de março de 1912, quatro anos depois, por não ter conseguido provar que realmente não tinha recursos financeiros para se manter (Arquivo do Asylo de Meninos Desvalidos pasta 003).

\section{Táticas de governo}

A partir dessas considerações preliminares, que dão a ver as regras de acesso dos meninos ao IPJA, o objetivo é interrogar o caráter de intervenção desta instituição nos corpos de seus estudantes ao investigar, para isso, fontes que evidenciam as táticas de governo voltadas para esses alunos e que estavam relacionadas ao cotidiano asilar. Para tornar esta investigação possível, procurei pensar disciplinas como Ginástica Escolar e as atividades do futebol como parte integrante das táticas de governo dos estudantes no IPJA.

Neste caso, elegi um corpus documental que fornece pistas para esta reflexão: os relatórios do diretor do IPJA. Dessa maneira, foi possível estabelecer interlocução com outros pesquisadores que se interessam por escrever a história dos marginalizados e com as contribuições teóricas de Michel Foucault, especialmente com sua noção de governamentalidade. 
Em busca de uma sustentação teórica, Jean-Claude Schmitt (1990) assinala as dificuldades de se definir a situação de marginalidade:

A priori é possível distinguir entre várias noções: a marginalidade que implica em estatuto mais ou menos formal no seio da sociedade traduz uma situação que, pelo menos em teoria, pode ser transitória. Para cá da marginalidade situa-se o conceito de integração (ou de reintegração), que indica a ausência (ou a perda) do estatuto de marginal dentro de uma sociedade; para lá da marginalidade, pelo contrário, situa-se o conceito de exclusão, que assinala uma ruptura - por vezes ritualizada - em relação ao corpo social. (Schmitt, 1990, p. 396)

Segundo Jorge Ramos do Ó, Michel Foucault (1979) cunhou o termo governamentalidade para identificar um tipo particular de literatura que, entre a segunda metade do século 16 e o final do século 18, se afirmou em torno de uma teoria proclamada como arte de governar, isto é, tecnologia de gestão de populações que, ao envolver a produção de dados, visava a gerir outras regularidades populacionais. Deste modo, a partir dessa formulação, considero que a classificação e reconhecimento das crianças pobres ou abandonadas conformam um tipo de população, para a qual serão pensadas medidas globais.

Ainda segundo Foucault,

a população aparece como sujeito de necessidades, de aspirações, mas também como objeto nas mãos do governo; como consciente, frente ao governo, daquilo que ela quer e inconsciente em relação àquilo que se quer que ela faça. O interesse individual - como consciência de cada indivíduo constituinte da população - e o interesse geral - como interesse da população, quaisquer que sejam os interesses e as aspirações individuais daqueles que a compõem - constituem o alvo e o instrumento fundamental do governo da população. Nascimento, portanto, de uma arte ou, em todo caso, de táticas e técnicas absolutamente novas. (1979, p. 289)

Portanto, inscrever o IPJA como objeto de investigação histórica significa entendê-lo como parte integrante da arte de governar crianças pobres, como dispositivo voltado para esse tipo específico de população. Nesse sentido, o governo estatal procurou organizar o Instituto para que exercesse um conjunto de funções: a casa que abriga, a escola que instrui e a oficina que profissionaliza (Souza, 2008), sendo que todo o conjunto deveria estar envolvido no projeto educativo (Escolano, 2001, p. 75).

$\mathrm{Na}$ tentativa de aprofundar nossas discussões, chega-se ao ponto de discutir sobre o caráter educativo dos exercícios físicos (ginásticos) no trabalho desenvolvido pelo IPJA. 


\section{Os exercícios ginásticos e a educação para o trabalho no IPJA}

Os meninos entraram todos analfabetos e em três meses já lêem com alguma correção. [...] este professor, jovem ainda, de robusta saúde, é dotado dos requisitos necessários a um bom mestre, pois, além de inteligência, tem o dom de insinuar-se e de cujas vontades facilmente dispõe. (AGCRJ - códice 13-3-6)

Os relatórios dos diretores da instituição analisada podem contribuir para a compreensão da importância do corpo saudável no espaço asilar/escolar. Ressonância dessa assertiva pode ser encontrada ainda no período imperial, como o exemplo do professor de primeiras letras do antigo Asilo de Meninos Desvalidos, posteriormente transformado no IPJA, Leopoldo Ribeiro Peres Machado.

Esse professor reunia um conjunto de atributos necessários ao exercício do magistério na instituição, tanto virtudes humanas quanto constituição física ideal. Inferese, então, que havia necessidade de que o corpo do professor reunisse determinados predicados, garantindo a visibilidade necessária para que pudesse exercer a autoridade sobre as condutas e vontades de seus alunos. Neste cenário, as fontes consultadas, datadas de 1881 a 1924, apresentam informações sobre os professores de ginástica do antigo Asilo de Meninos Desvalidos e IPJA.

\section{Quadro 1}

Professores de exercícios físicos no Asilo/IPJA.

\begin{tabular}{|l|l|l|}
\hline \multicolumn{1}{|c|}{ Disciplina } & \multicolumn{1}{|c|}{ Professor } & \multicolumn{1}{c|}{ Período } \\
\hline Ginástica & $\begin{array}{l}\text { Manoel de Azambuja } \\
\text { Monteiro }\end{array}$ & 1881 \\
\hline Ginástica & Paulo Vidal & 1882 a 1885 - 2 anos \\
\hline $\begin{array}{l}\text { Ginástica } \\
\text { Ginástica }\end{array}$ & $\begin{array}{l}\text { Arthur Higgins } \\
\text { Sylvio Washington }\end{array}$ & $\begin{array}{l}1887 \text { a 1889 - 2 anos } \\
1924 \text { a } ?\end{array}$ \\
Exercícios Militares & $\begin{array}{l}\text { Guimarães } \\
\text { Cel. Luis Furtado }\end{array}$ & $\begin{array}{l}\text { (1924 a ? (sem função no } \\
\text { IPJA) }\end{array}$ \\
\hline
\end{tabular}

Fonte: Almanak Laemmert, 1888; Códice 38-3-36 (AGCRJ) e Braga (1925). 
Dentre os citados, destacamos as ações do professor Arthur Higgins ${ }^{6}$ que difundiu a idéia de um corpo saudável ${ }^{7}$ por meio de estudos como o Compendio de Gymnastica Escolar. Este, para Silva (1999),

não constitui apenas um manual pedagógico que foi indicado oficialmente como livro didático para as escolas publicas do Rio de Janeiro, mas nele está contido a compreensão do corpo e da atividade física daquela época (p. 30).

É preciso registrar, ainda, que Artur Higgins (1860-1934), professor de ginástica no antigo Asilo de Meninos Desvalidos entre os anos de 1887 a 1889, foi um profissional de expressão no cenário educacional da Corte, sendo o principal responsável pela difusão do ensino de ginástica nas escolas do Município Neutro. Dentre outras contribuições para a educação pública, Higgins, em 1899, introduziu o futebol no Brasil, jogando com os alunos do Externato Pedro $2^{\circ}$ no Campo de Santana (Velho Sobrinho, 1940).

Em 1924, no relatório do diretor interino José Theodoro Braga ${ }^{8}$, é possível captar ecos de práticas administrativas anteriores e da organização da ginástica escolar criticadas pelo diretor. De acordo com o relato de Braga, ele havia encontrado

um dos serviços que, embora posto em prática durante muitos anos, não satisfazia, a [seu] ver, as múltiplas exigências de várias obrigações as quais, sem uma disposição inteligente e coordenada, redundariam em confusão e inutilidade. Estudei bem todos esses serviços e obrigações e conclui haver necessidade urgente de alterar o que havia para, pondo em ordem de concatenação, obter horas em que os educandos pudessem tranquilamente estudar as suas lições sem os atropelos das aulas, oficinas

\footnotetext{
${ }^{6}$ Artur Higgins (1860-1934). Nasceu em Petrópolis e faleceu no Rio de Janeiro. Filho de Artur Felipe Higgins, da Filadélfia, e de Marcolina da Silva Lima Higgins, professora particular, com quem fez os estudos primários. Na Escola Normal da Corte, em 1883, fez o Curso Secundário, sendo o único aluno aprovado com distinção em ginástica, em 1884, mostrando, assim, um franco pendor para a matéria de que, mais tarde, seria professor. Formou-se nesta escola e neste ano. Foi, em 1886, nomeado seu professor interinamente e efetivado em 1890. Ensinou essa matéria no Colégio Pedro $2^{\circ}$, na Escola Normal, nos Colégios Alfredo Gomes, Mairink, São José e muitos outros, aliando ao ensino de ginástica evoluções militares e esgrima. Em 1899, introduziu, no Brasil, o foot-ball, jogando com os alunos do Externato Pedro $2^{\circ}$ no Campo de Santana. Aposentando-se nesse externato, onde lecionava desde 1884 , jubilando-se, também, na Escola Normal, após 40 anos de exercício efetivo, entregou-se a estudos, tendo sido o brasileiro que obteve mais patentes de invenção. Alcançou seis medalhas de ouro, grande prêmio, elogios e diplomas de honra, que o governo lhe conferiu na Exposição do Centenário de 1922. Em 1880, foi repórter do O Cruzeiro e fundou, em 1881, O século 19; em 1882, A lente; e em 1883, A lanterna de Diógenes, jornais que eram vendidos a 20 reis. Residindo à rua Caruaru, n. 1, faleceu no Hospital Evangélico, deixando viúva a professora Hortência Rosada Higgins. Escreveu, dentre outros, O vencedor vencido (romance iniciado inédito). Fonte: Dicionário biobibliográfico de Velho Sobrinho, 1940.

7 "Uma iniciativa importante de ordem legislativa aconteceu em 1854, com o então ministro Couto Ferraz incluindo a Ginástica como obrigatória no ensino primário e a dança como obrigatória no ensino secundário. Logo, entende-se que estas ações proporcionaram uma sistematização de cultura física no Brasil. Novos instrutores eram formados também na antiga Escola Normal da Corte, entre eles um que se destaca historicamente pela sua produção sobre ginástica escolar, no fim do século 19: Arthur Higgins". (Cunha Júnior, 1999, p. 1325, apud, Magalhães, 2005, p. 92).

8 José Theodoro Braga (1872-1953), professor e diretor interino do Instituto Profissional João Alfredo. Pintor, historiador da arte, ilustrador, decorador, professor e diretor interino do Instituto Profissional João Alfredo. Disponível em: http://www.itaucultural.org.br. Acesso em março de 2009.
} 
e recreio. Das meticulosas observações feitas resolvi mudar esse horário, dividindo o dia em duas metades, sendo a primeira, matinal, destinada às aulas do curso de adaptação e a segunda, postmeridiana, às oficinas. (Braga, 1925, p. 166)

Com fins didáticos, pergunta-se: como deveria ser o funcionamento do IPJA e qual o espaço da ginástica escolar em sua proposta administrava? O referido diretor entendia 0 IPJA como uma casa de educação onde "eram atendidos somente meninos pobres e onde o município zelava pela instrução, educação e robustez destes" (Braga, 1925, p. 197).

Assim, para garantir que não permanecesse a "confusão e a inutilidade" da gestão anterior, cuidou da administração do tempo no complexo asilar/escolar. Com esse fito, escreveu sobre a sua pretensão e a encaminhou para Antonio Carneiro Leão, Diretor Geral de Instrução Pública, em 20 de junho de 1924, que prontamente o respondeu:

Snr. Diretor do Instituto Profissional João Alfredo

Respondendo ao vosso oficio $\mathrm{n}^{\circ} 128$, de 6 do andante, autorizo-vos a adotar o horário que organizastes para os trabalhos desse Instituto e o qual com este devolvo com o meu Aprovo. Saudações. O Director Geral Antonio Carneiro Leão. (Fonte: Arquivo do Asylo de Meninos Desvalidos. Proedes/FE/UFRJ. Códice: Ofícios recebidos - 14 de janeiro de 1924 a 31 de dezembro de 1926 - Instituto Profissional João Alfredo).

De posse da aprovação daquela Diretoria, Braga fez, então, a distribuição dos horários das aulas por turmas (tabelas 1 e 2).

\section{Quadro 2}

Distribuição do tempo asilar/escolar no IPJA - 1924.

\begin{tabular}{|l|c|}
\hline \multicolumn{1}{|c|}{ Horário } & Atividade \\
\hline Às 5h50min & Café \\
\hline Das 6h10min. às 7h50min & Ginástica \\
\hline Das 7h50min. às 8h & Fórma \\
\hline Das 8h às 11h & Aulas \\
\hline Das 11h às 11h30min. & Almoço \\
\hline Das 11h30min. às 12h & Descanso \\
\hline Das 12h às 16h & Oficinas \\
\hline Das 16h às 17h & Banho \\
\hline Das 17h às 17h40min. & Jantar \\
\hline Das 17h40min. às 18h20min. & Descanso \\
\hline Das 18h20min. às 20h & Estudos \\
\hline Das 20h às 20h15min. & Ceia \\
\hline Das 20h15min. às 21h & Dormitório \\
\hline Às 21h & Silêncio \\
\hline
\end{tabular}

Fonte: Braga, 1925, p.155-190. ${ }^{9}$

${ }^{9}$ Os quadros 2 e 3 foram produzidos pela autora deste estudo a partir do relatório de José Theodoro Braga do ano de 1924. 
Quadro 3

Distribuição das turmas demais atividades no IPJA - 1924.

\begin{tabular}{|l|l|l|}
\hline \multicolumn{1}{|c|}{ Cursos } & \multicolumn{1}{c|}{ Turmas } & \multicolumn{1}{c|}{ Horário } \\
\hline Primeiras letras & Atrasada & Diariamente (matutino) \\
\hline & Adiantada & \\
\hline Modelagem & Atrasada & \\
\hline & Médias & \\
\hline & Atrasada & \\
\hline Atividades físicas & & $6 \mathrm{~h} 10 \mathrm{~min}$. às 7h50min. \\
\hline Ginástica & & \\
\hline Educação e trabalho & & $12 \mathrm{~h}$ às 16h \\
\hline Oficinas & & \\
\hline
\end{tabular}

Fonte: Braga, 1925, p.155-190.

Explica-se que o Curso de Letras era ministrado na parte da manhã e diariamente para o ensino de primeiras letras. A partir do $2^{\circ}$ até o $3^{\circ}$ ano escolar, as aulas deste curso eram ministradas as terças, quintas e sábados. Em relação aos demais cursos de artes, profissional e ofícios, apenas o primeiro deles era matinal, realizando-se três vezes por semana; os outros, diariamente e à tarde.

Nessas condições, os estudantes teriam trabalhos nas seguintes oficinas: de madeira, em metal, em tinta e estuque, em couro, em trabalhos rurais e eletrotécnica. Sobre essa última oficina, Braga (1925) queixava-se da necessidade de um curso teórico de eletricidade ser oferecido pela manhã, de modo que a tarde ficasse reservada para os trabalhos com a parte prática dessa teoria.

No que diz respeito à estreita ligação entre educação e o trabalho que os meninos executavam, há tensões explícitas no relatório do diretor José Rodrigues de Azevedo Pinheiro, do ano de 1899. A primeira se encontra diretamente ligada às famílias dos alunos que retiravam seus filhos do IPJA antes de se formarem, argumentando que conseguira um emprego remunerado.

A outra queixa é feita pelo diretor aos meninos, principalmente os da Banda de Música, admitidos como praças nas Bandas do Exército e do Esquadrão de Cavalaria da Polícia sem haver desligamento oficial do Instituto. Uma terceira e última observação do diretor José Rodrigues de Azevedo Pinheiro sublinha a existência de prejuízo para o ensino profissional em detrimento do lucro nos seguintes termos:

o que quer é produzir, produzir sempre de modo que a renda seja animadora e sejam satisfeitos os que pretendem fazer do Instituto um centro de grandes lucros. Estas duas maneiras de se ver se repelem: o Instituto ou é um estabelecimento de ensino ou de venda. O ensino 
multiplica a venda, a procura da venda sacrifica o ensino. (AGCRJ, códice 38-3-36)

Em relação às duas primeiras queixas de José Rodrigues de Azevedo, segundo Cunha (2005), demonstram preocupações com o alto custo do ensino profissional ministrado em regime de gratuidade e no regime de internato. Nesse sentido, não se poderia admitir desistência do curso, posto que, nestes casos e sob esta ótica, a instituição não teria conseguido cumprir plenamente sua finalidade. Sobre a última queixa, há indícios de que esse diretor buscou afastar os educandos do trabalho com fins lucrativos.

Quanto às oficinas, Braga (1925) também se questionava da distância entre estas e o prédio principal, após a mudança do Asilo São Francisco de Assis ${ }^{10}$ para a Chácara dos Macacos, em 1921:

afastadas as oficinas do almoxarifado torna-se penoso todo o trabalho de alunos ou de encomendas, pelas necessidades dos mestres em pedirem e fazerem buscar o material necessário daquele departamento (p. 172).

Ademais, pela racionalização na distribuição do tempo e no horário das aulas, Braga (Idem) evidenciou que o espaço de vivência no IPJA seria regido por meio de disputas de poder. Tendo isso em vista, planejou modificações que pudessem controlar a vida dos estudantes naquela

longa distancia, [num] espaço desabrigado, no vai e vem continuo de um para outro lado, levam os educandos em correrias contínuas e nocivas, ora inúteis, ora a mandado, fazendo-se elas em um declive bastante acentuado, já em terra batida e em uma escadaria alternada de três degraus com terra-plenos (sic) irregulares; acresce que nos dias de chuva ficam os educandos enlameados e encharcados, não servindo nem mesmo, um barracão aberto e de telhado já todo esburacado, para protegê-los, quando em recreio nestes dias chuvosos (p. 172).

Para justificar junto aos seus superiores que os trabalhos nas oficinas seriam de difícil execução, Braga (Ibidem) os elencou a partir dos seguintes argumentos:

Com efeito, a situação no campo, e longe da administração, em que se acham instaladas, em seis edifícios e sem capacidade, nem conforto, as 10 oficinas deste Instituto, é, por vários motivos, assaz prejudicial ao adiantamento coordenado dos educandos: $1^{\circ}$ porque a situação de um edifício para com outro, as suas aberturas ou portas, a falta de conforto interno não permitem o interesse do educando pelo aprendizado do ofício, ao mesmo tempo que impossibilita toda e qualquer inspeção eficiente

\footnotetext{
${ }^{10}$ Atualmente, este Asilo funciona sob a responsabilidade da municipalidade, e sua transferência do centro da cidade para o espaço do Instituto Profissional João Alfredo se deu em 1921. Na Chácara dos Macacos, espaço antes ocupado pelo IPJA, funcionam, hoje, o referido Asilo para idosos, a Escola Argentina e o Hospital Universitário Pedro Ernesto. Instituições que dividem espaço com o atual Colégio Estadual João Alfredo, antigo IPJA. Endereço: Av. 28 de Setembro, 109. Vila Izabel - Rio de Janeiro.
} 
máxime com a exigüidade de inspetores; $2^{\circ}$ porque estando longe do edifício principal da administração ficam essas oficinas ao desabrigo de qualquer vigilância, sobretudo durante á noite, facilitando assim surpresas desagradáveis de invasão; $3^{\circ}$ porque afastadas de cerca de 160 metros do edifício principal onde se acham as aulas, dormitórios, refeitório, etc. ( $p$. 172)

Ao longo de seu relatório, de modo insistente, Braga (1925) salienta que todos aqueles problemas tinham uma causa única: a mudança do Asilo de São Francisco de Assis

para a maior e melhor metade do edifício de propriedade deste Instituto. Houve tal pressa e negligência nesse trabalho mal feito de adaptação, que se não cogitou das devidas instalações das diferentes dependências deste estabelecimento de instrução e de educação, deslocadas e atiradas, desse modo, onde á primeira vista parecia mais conveniente a pressa de mudar do que ás prementes necessidades e ao valor de cada uma delas. Acresce, mais que o autor do projeto desses pardieiros (porque outra cousa não são eles) esqueceu-se, certamente, de que construía para um estabelecimento que interna cerca de 400 crianças irrequietas e irresponsáveis. (p. 172)

Enfim, um rosário de queixas em que prevaleceram as questões voltadas para o bom andamento do trabalho nas oficinas. Aliás, estes ambientes encontravam-se com o telhado esburacado, apresentando goteiras que danificavam o maquinário, devido a dois motivos: não havia a "devida inclinação das telhas que escorregam com os ventos fortes" e pelo fato de terem sido quebradas "pelo antigo uso, hoje proibido, do futebol de tristissíma memória" (Idem, p. 179). Finalmente, a oficina de metais é descrita como de uma só porta, tendo, ao alto, três mezaninos cujas vidraças estavam, inteiramente, quebradas, também em função do jogo de futebol, circunstância esta que merece destaque a partir de agora.

\section{Os diretores, os meninos e o futebol de tristíssima memória}

Como já apresentado, não era apenas o futebol que incomodava a direção do IPJA, mas também "estrados, mesas, quadro negros, tudo entre paredes que pedem limpeza e uma pintura clara para alegrar um pouco desta angustia em que se vive" (Braga, 1925, p. 180). É importante registrar que não eram poucos os moradores da Chácara dos Macacos, local de funcionamento do conjunto arquitetônico, denominado IPJA, formado pela casa, a escola e as oficinas.

Dentre eles, cerca de 400 crianças são descritas, como irrequietas e irresponsáveis na vida movimentada do IPJA. Especialmente para elas, o Serviço Clínico cuidou para que a rotina de suas vidas não sofresse "abalos nem tristezas". A fim de garantir tal 
intento, o futebol, novamente, ocupou a agenda de Braga, com a sua afirmação de que o médico da instituição não precisaria mais se preocupar com as crianças feridas e com os imensos dispêndios advindos do jogo em questão. Para ele, a proibição do jogo de futebol se constituía igualmente em uma questão econômica.

Ao tratar dos momentos em que os estudantes encaminhavam-se para o recreio, o diretor apresenta apenas o lado negativo, mencionando que "torna-se de difícil inspeção pela obstrução desses edifícios de tamanhos e situações diferentes, permitindo esconderijos e travessuras perigosas" (Braga, 1925, p. 172).

Com relação aos exercícios saudáveis, Braga destaca aqueles provenientes da ginástica sueca, cuja prática se restringia ao ambiente escolar:

Desde julho que apresentados por vós [Diretoria de Instrução Pública], os primeiros tenentes Maurício B. de Araújo e Vicente Lopes Pereira, da Brigada Militar de Polícia, tem vindo exercitando os educandos nos salutares exercícios da ginástica sueca. Infelizmente, as graves perturbações da Paz da Família interromperam constantemente aqueles úteis ensinamentos pelo afastamento, quase sempre, daqueles distintos militares obrigados a permanecerem nos seus postos. (Idem, p.190)

É provável que, nesta oportunidade, o diretor tenha-se referido ao movimento que eclodiu no segundo semestre do ano de 1924, quando se registrou um dos períodos mais conturbados da história brasileira nas principais cidades do país: eram os motins nos quartéis, os quais sofriam influência do que já ocorrera em 1922, com o chamado levante do Forte de Copacabana (Fausto, 2006). Em resumo, no IPJA, Braga mantinha a esperança de "que, sufocada completamente toda e qualquer tentativa de desordem, voltarão [voltariam] a ter aqueles exercícios os educandos que muito têm lucrado" ( $p$. 190).

Do ponto de vista político, os diretores idealizavam uma cidade progressista e ordeira. Para tanto, defendiam a inserção social das crianças pobres por meio da educação para o trabalho,

configurando este quadro de preocupações de ordem preventiva, a partir do qual se tentava imprimir novas tonalidades ao colorido urbano da Capital, deve-se destacar, principalmente, a fase inicial da administração Pereira Passos. Afinal, foi nesse período que o prefeito procurou atrelar e fundir ao movimento do "bota-abaixo" a difusão de regras de sociabilidade, tendo como objetivo último a adoção de comportamentos sadios e preventivos por parte dos habitantes. Coibição de serenatas; perseguição às prostitutas, aos mendigos, capoeiras, vadios, malandros, cafetões, boêmios; proibição de urinar e escarrar em localidades públicas, de empinar pipas, de acender fogueira e fogos de artifícios, de brincar o entrudo foram algumas das medidas implementadas e/ou atualizadas pelo Prefeito. (Silva e Souza, 2008, p. 8) 
Anos depois, em 1920, o governo estatal encomendou um código de posturas a Francisco Mariano do Amorim Carrão. Assim, era desejo expresso do prefeito do então Distrito Federal que o mesmo fosse dotado de um "Moderno Código de Posturas, inadiável à vista do extraordinário desenvolvimento dos serviços municipais e em razão da notável expansão da cidade" (Códice 35-2-6, p. 201). Portanto, o espaço que se imaginava para viver era um espaço projetado, isto é, planejado.

Sob a ótica poética, os meninos sonhavam com o futebol. Também na busca por um ideal, Arthur Higgins sonhava com progresso e com ordem. Para isso, elaborou exercícios e os difundiu, no cenário educacional do Rio de Janeiro, por meio do ensino de gymnástica nas escolas desta cidade. Finalmente, em 1899, introduziu o futebol, jogando com os alunos do Externato Pedro $2^{\circ}$, no Campo de Santana. Entretanto, como já comentado, Braga proibiu o futebol anos depois no IPJA, alegando que havia restado desta prática, entre os meninos, apenas uma “tristíssima memória”!

\section{Considerações finais}

Retomando a epígrafe apresentada no início deste estudo, concordo com Eliane Marta Lopes (2010) sobre o fato de que a literatura não reflete a vida escolar, mas revela uma realidade que escapa à pesquisa histórica. Dentro do nosso contexto de estudo, alerta, por exemplo, para os sentimentos que envolveram a vivência dos meninos no cotidiano asilar/escolar do IPJA, quando foram proibidos de jogar futebol. Porém, essa mesma literatura ressalta que esses sentimentos são possíveis de serem pensados apenas por inferências, as quais indicam o retorno desses meninos às "suas tristes vidas", uma das expressões utilizadas por Braga.

Apesar disso, quando a questão incide no governo dos corpos infantis, inquire-se acerca do modo de governá-los, uma vez que a gestão ou conciliação entre diferentes saberes não se mostrou possível, como no caso da ginástica escolar que não comportou o futebol. A exclusão desse tipo de atividade do interior do Instituto é justificada pelo desvio que promovia em relação a uma das funções primordiais do dispositivo, isto é, o futebol comprometeria o desenvolvimento das atividades produtivas.

De fato, a intenção dos gestores da instituição examinada era incutir obediência física e moral, como técnica para obter rentabilidade máxima. Neste caso, tratava-se de sujeitar os corpos infantis por meio de diferentes restrições: controle do horário e aumento da quantidade de inspetores para a produção de uma vigilância eficaz.

Contudo, ao se posicionar sobre os momentos de recreio dos educandos, Braga relatou a dificuldade de conter esses alunos, devido ao espaço da Chácara ser obstruído 
por edifícios de tamanhos e situações diferentes. Além dessas condições, o futebol era visto pelo diretor como a atividade que mais inquietava os educandos, argumento empregado para a proibição. O entendimento do futebol como prática não escolar, deseducativa não Ihe era exclusiva.

Lima Barreto, seu contemporâneo, também duvidava que este esporte fosse capaz de cumprir tal função. Nas suas palavras o futebol "é uma escola de violência e brutalidade e não merece nenhuma proteção dos poderes públicos, a menos que estes nos queiram ensinar o assassinato" (Lima Barreto, 1922, apud Santos Augusto, 2006, p. 4).

Outro aspecto que merece ser lembrado refere-se à gestão de Braga. O diretor lutou para que o IPJA se tornasse uma instituição moderna com planejamento adequado quanto à sua arquitetura, distribuição racional do tempo escolar e do trabalho. Para tanto, reforçou o movimento de homogeneização e uniformização que ocorria, provocando diferenciações: turmas atrasadas, médias, adiantadas, educando/criança irrequieta.

De certo, deixou registrado que o IPJA era parte do ideário de modernidade, uma expressão de gestão científica preconizada em seu tempo. No entanto, alegava que a "pressa e a negligencia" no trabalho "mal feito de adaptação" conduzira os arquitetos a projetarem "pardieiros" que tratava de denunciar e combater.

Em vista disso, percebe-se que esta é uma história de desejos de alguns e de realizações de outros. Em termos mais específicos, representa os desejos daqueles meninos que não mais puderam alegrar as suas vidas, pelo menos enquanto estudantes/moradores do IPJA, com uma prática daquilo que, provavelmente, gostavam de fazer: jogar futebol. Entretanto, para um dos diretores do Instituto, José Theodoro Braga, prevalecia o entendimento de que o jogo de futebol era nocivo aos estudantes e anti-econômico, o que o levara a proibir tal prática no interior do Instituto.

Por fim, o gesto de interdição implica refletir a respeito dos sentidos atribuídos à ginástica escolar, função do futebol no interior desse campo de saber, os agentes e ação dos internos. Além disso, configura um convite àqueles que se interessam pelo estudo dessa temática. Sem mais comentários, cedo a palavra para José Lins do Rego, como forma de apontar para outro escuro silêncio da história da institucionalização de meninos órfãos. Afinal, como os meninos lidaram com as rotinas institucionais e que efeitos a disciplina interna afetou os corpos e as vidas e que efeitos proporcionou na gestão dessa população de pequenos?

Este primeiro dia de colégio, eu o venci pensando nos outros. Agora tudo me parecia diferente. A experiência de seis meses dera-me coragem de 
olhar o resto do ano com virilidade. Em janeiro um pobre novato caira nas garras de Seu Maciel, à-toa, sem saber de nada. Ele fizera de mim o que bem quizera. Agora voltara mais homem, olhando as cousas com superioridade. Ninguém se colocaria acima de mim, via os colegas sem os ligar, num plano inferior, sabendo todos os segredos do colégio. (Rego, 1977, p. 131)

\section{Referências}

ESCOLANO, Agustín. Arquitetura como programa: espaço-escola e currículo. In: FRAGO, Antonio Viñao; ESCOLANO, Agustín. Currículo, espaço e subjetividade: a arquitetura como programa. Rio de Janeiro: DP\&A, 2001, p. 19-47.

FARIA FILHO, Luciano Mendes de. Cultura e práticas escolares: escrita, aluno e corporeidade. Cadernos de Pesquisa, n. 103, 1998, p. 136-149.

FAUSTO, Boris. História geral da civilização brasileira: sociedade e instituições (18991930). Rio de Janeiro: Bertrand Brasil, 2006.

FOUCAULT, Michel. Arqueologia do saber. Rio de Janeiro: Forense, 1995.

FOUCAULT, Michel. Microfísica do poder. Rio de Janeiro: Graal, 1988.

FOUCAULT, Michel. Vigiar e punir: nascimento da prisão. Petrópolis. Vozes, 1987.

FOUCAULT, Michel. Segurança, território, população. São Paulo: Martins Fontes, 2008.

GOMES-DA-SILVA, Pierre Normando. Compendio de gymnastica escolar: o corpo e a pedagogia no início do século 20. In: FERREIRA NETO, Amarílio (org.). Pesquisa histórica na educação física. Aracuz: Facha, 1999, p. 27-49.

GONDRA, José G. Artes de civilizar: medicina, higiene e educação escolar na Corte Imperial. Rio de Janeiro: Uerj, 2004.

LOPES, Eliane Marta. Educação é um romance. Texto mimeografado, 2010.

MAGALHÃES, Henrique Ferreira. Breve histórico da educação física e suas tendências atuais a partir da identificação de algumas tendências. Revista da Educação Física, UEM. Maringá, v. 16, n. 1, 2005, p. 91-102.

RAMOS DO Ó, Jorge. A governamentalidade e a história da escola moderna: outras conexões investigativas. Revista Educação e Realidade, Porto Alegre: Ufrgs, v. 34, n. 2, 2009, p. 97-118.

REGO, José Lins do. Doidinho. Rio de Janeiro: José Olimpyo, 1977.

ROCHA, Heloisa Helena Pimenta. Prescrevendo regras de bem viver: cultura escolar e racionalidade científica. Cadernos Cedes. Campinas: Unicamp, n. 52, 2000, p. 55-73.

SCHMITT, Jean-Claude. A história dos marginais. In: LE GOFF, Jacques et al (org.). A nova história. Coimbra: Almedina, 1990.

SANTOS AUGUSTO, Emília Carolina dos. Olho no lance: futebol e modernidade na crônica de Lima Barreto. Disponível em: <http://www.ri.anpuh.org/resources/rj/Anais/2006/ conferencias/Emilia\%20Carolina\%20Bispo\%20dos\%20Santos\%20Augusto.pdf.> Acesso em: 17 out. 2011.

SOUZA, Maria Zélia Maia de. Educar, trabalhar e civilizar no Asilo de Meninos Desvalidos (1875-1894): caminhos possíveis. Rio de Janeiro: UFRJ, 2008. 114f. Dissertação (Mestrado em Educação). Universidade Federal do Rio de Janeiro. 
SILVA, José Claúdio Sooma. Educar os corpos, afastar os perigos: as contribuições da ginástica escolar na remodelação urbana carioca. CONGRESSO BRASILEIRO DE HISTÓRIA DA EDUCAÇÃO, 5, 2008, Aracajú. Anais ... Aracajú: SBHE, 2008.

RIZZINI, Irma. Uma casa de educação: o ensino integral no Asilo de Meninos Desvalidos (1875-1894). In: CHAVES, Miriam Waidenfeld; LOPES, Sonia (orgs.). Instituições educacionais da cidade do Rio de Janeiro: um século de história (1859-1950). Rio de Janeiro: MauadX- Faperj, 2009, p. 57-82.

VARELA, Júlia; ALVAREZ-URIA, Fernando. A maquinaria escolar. Teoria e Educação. Porto Alegre: Pannonica, n. 6, 1992, p. 68-96.

VEIGA, Cynthia Greive. História da educação social: um campo de investigação para a história da educação. CONGRESSO BRASILEIRO DE HISTÓRIA DA EDUCAÇÃO, 6, 2011, Vitória. Anais ... Vitória: Universidade Federal do Espírito Santo/SBHE, 2011.

\section{Arquivo Nacional}

FONSECA, Alvarenga. Coleção de leis municipais e vetos de 1892-1894. Rio de Janeiro: Typografia do Jornal do Commércio, 1897.

\section{Biblioteca Nacional}

Obras gerais

BRAGA, Theodoro José da Silva de Medeiros. Subsídios para a memória histórica do Instituto Profissional João Alfredo - desde a sua fundação até o presente - 1875 - 14 de março de 1925 - Rio de Janeiro: Santa Cruz, 1925. 213 págs. BN: I 215,4,5.

Obras raras

SOBRINHO, Velho. Dicionário biobibliográfico. Ministério da Educação e Saúde. Rio de Janeiro, 1940, 2V. BN 015.81 V436d V. 12.

\section{Arquivo Geral da Cidade do Rio de Janeiro}

Série Instrução Pública:

Códice 11-4-27, 1875-1879, número de páginas: 151.

13-3-36, Asilo de Meninos Desvalidos, Ensino profissional e Comercial. Papéis separados por ordem cronológica. 1875-1880.

35-2-6, Ofícios do copiador, 1920.

38-3-36, Relatórios dos Institutos Profissionais, 1899-1900.

\section{Arquivo dos Asylos dos Meninos Desvalidos}

UFRJ/FE/Proedes.

Códice, Ofícios recebidos de 14 de janeiro de 1924 a 31 de dezembro de 1926. 
MARIA ZÉLIA MAIA DE SOUZA é estudante do curso de doutorado em Educação na Universidade Federal de Minas Gerais - UFMG.

Enderço: Rua Aparaí, 676 - 22765-670 - Rio de Janeiro - RJ - Brasil.

E-mail: zeliammaia@yahoo.com.br.

Recebido em 10 de março de 2012.

Aceito em 28 de maio de 2012. 